\title{
Apolipoprotein C-III in the high-density lipoprotein proteome of cerebral lacunar infarction patients impairs its anti-inflammatory function
}

\author{
PU LV ${ }^{1}$, MINGMING ZHAO ${ }^{2}$, YUANYUAN LIU ${ }^{3}$, HAIQIANG JIN $^{3}$, WEI CUI ${ }^{3}$, CHENGHE FAN $^{3}$, \\ YUMING TENG ${ }^{3}$, LEMIN ZHENG $^{2}$ and YINING HUANG ${ }^{3}$ \\ ${ }^{1}$ Department of Health Care, China-Japan Friendship Hospital, Ministry of Health, Beijing 100029; \\ ${ }^{2}$ The Institute of Cardiovascular Sciences and Institute of Systems Biomedicine, School of Basic Medical Sciences, \\ and Key Laboratory of Molecular Cardiovascular Sciences of Ministry of Education, \\ Key Laboratory of Cardiovascular Molecular Biology and Regulatory Peptides of Ministry of Health, \\ Peking University Health Science Center, Beijing $100191{ }^{3}$ Department of Neurology, \\ Peking University First Hospital, Beijing 100034, P.R. China
}

Received January 5, 2016; Accepted October 17, 2017

DOI: $10.3892 / \mathrm{ijmm} .2017 .3216$

\begin{abstract}
High-density lipoprotein (HDL) proteomic study has identified substantial changes associated with various disease states. In the current study, the HDL proteomes in patients with cerebral lacunar infarction (LACI) and control subjects were investigated. A total of 12 LACI patients without evident large vessel occlusions and 12 controls were enrolled in the study. The HDL fraction from each sample was isolated from the plasma by ultracentrifugation. The protemics of the HDL were investigated using nano liquid chromatography coupled to tandem mass spectrometry. There were 55 proteins identified as differentially expressed in the LACI and control groups. Among the 55 proteins, 33 were upregulated and 22 were downregulated in the patients with LACI. The identified proteins were associated with numerous molecular functions, including lipid and cholesterol transport, lipid metabolism, inflammatory response, the complement and coagulation pathway, metal ion
\end{abstract}

Correspondence to: Professor Yining Huang, Department of Neurology, Peking University First Hospital, 8 Xishiku Street, Xicheng, Beijing 100034, P.R. China

E-mail: ynhuang1@126.com

Dr Lemin Zheng, The Institute of Cardiovascular Sciences and Institute of Systems Biomedicine, School of Basic Medical Sciences, and Key Laboratory of Molecular Cardiovascular Sciences of Ministry of Education, Key Laboratory of Cardiovascular Molecular Biology and Regulatory Peptides of Ministry of Health, Peking University Health Science Center, 38 Xueyuan Street, Beijing 100191, P.R. China E-mail: zheng1@bjmu.edu.cn

Key words: high density lipoprotein, lacunar infarction, apolipoprotein C-III, anti-inflammatory metabolism, hemostasis and endopeptidase inhibitory activity. Serum amyloid A, apolipoprotein C (apoC-III) and apolipoprotein A-II (apoA-II) were selected to confirm the proteomics results via western blotting. HDL from the LACI patients exhibited an impaired ability to inhibit the binding of THP-1 cells to endothelial cells compared with the controls $(\mathrm{P}<0.01)$. ApoCIII-rich HDL also had a significantly reduced ability to inhibit the binding of THP-1 cells to endothelial cells $(\mathrm{P}<0.01)$. The expression of vascular cell adhesion molecule-1 protein by the endothelial cells exhibited a similar pattern of response to the different HDL samples. In conclusion, the present study demonstrates major modifications of the HDL proteome in patients with LACI. The ApoC-III enrichment of the HDL of patients with LACI may cause a reduction in the anti-inflammatory ability of HDL, which may contribute to the progression of the disease.

\section{Introduction}

High-density lipoprotein (HDL) particles are particles with a density of $1.063-1.210 \mathrm{~g} / \mathrm{ml}$ that are composed of proteins and lipids (1). Compared with other lipoproteins, HDL contains a high level of protein. The protein/lipid ratio differs among HDL subpopulations. In the large and light HDL subfraction HDL2, the ratio is 1:2, and in small dense pre-HDL it is 10:1 (2). Apolipoprotein A-I (apoA-I) is the most abundant protein component (3) in HDL particles. ApoA-I constitutes $~ 70 \%$ of the protein content of HDL, followed by apoA-II, which constitutes $15-20 \%$ (4). The remaining proteins include apolipoprotein $C$ (apoC-I, apoC-II and apoC-III), apolipoprotein E (apoE), apolipoprotein $\mathrm{D}$ (apoD), apolipoprotein M (apoM), apolipoprotein A-IV (apoA-IV) and other proteins that are involved in lipid metabolism, including lecithin:cholesterol acyl transferase and cholesteryl ester transfer protein. Proteomic studies (5-8) have identified $\geq 75$ different proteins that are contained in HDL obtained by ultracentrifugation. 
Regarding disease states, HDL proteomic studies have observed substantial changes in HDL in individuals with cardiovascular disease (8-11), diabetes mellitus (DM) (12), chronic kidney disease (13-15) and rheumatoid arthritis (16) in comparison with healthy individuals, while the plasma HDL-cholesterol (HDL-C) did not change markedly $(8,9)$. Disorders such as atherosclerosis and type 2 DM cause a prominent chronic inflammatory state affecting endothelial cells, which induces a proteomic change of HDL with the subsequent impairment of their antiatherogenic, antioxidant and anti-inflammatory functions (17). HDL subpopulations are associated with stroke subtype; a previous study identified that smaller HDL-C particles were associated with a reduced risk of lacunar infarction (LACI) (18).

The biological mechanism underlying the beneficial role of small HDL particles in LACI is not well understood. It is considered that the anti-inflammatory effects of smaller HDL particles $(19,20)$ inhibit angionecrosis or microatheroma formation in cerebral vessels, and thereby reduce the risk of LACI $(21,22)$. Proteomics may be helpful in identifying the molecules associated with HDL that intervene in their inverse association with cerebrovascular disease, as the quantitative measurement of HDL-C level does not explain this satisfactorily (23). Proteomic analysis may drive a shift in the classical classification of HDL subfractions, from the previous physicochemical model towards a novel pattern based on their physiological function and pathophysiological roles $(24,25)$. In the present study, the HDL proteomes in patients with LACI and controls were investigated.

\section{Materials and methods}

Ethics statement. The study was approved by the Ethics Committee of Peking University First Hospital (Beijing, China). Written informed consent was provided by all patients and controls.

Subjects and biochemical analysis. The study included 12 patients with LACI ( 7 males and 5 females, aged $45-69$ years old) without any evident large vessel occlusions and 12 control subjects ( 7 males and 5 females, aged 48-62 years old). The patients and controls were recruited in the Neurology Ward of Peking University First Hospital from January 1, 2015 to March 31, 2015. Exclusion criteria were having infectious, inflammatory or autoimmune disorders, advanced kidney or liver failure, neoplastic disease, and a history of major surgery or trauma within the previous month. Patients with LACI were defined as having lacunar syndrome and signs, and brain neuroimaging evidence of an infarct of size $\leq 1.5 \mathrm{~cm}$ at a typical location $(26,27)$. The patient and control groups were equivalent with regard to sex proportion and age range. Blood samples were drawn into EDTA-coated tubes following an 8-h fast. Fasting blood glucose and creatinine were determined using a Beckman CX5 Automated Analyzer. DM was defined either as records of fasting blood glucose $>7.0 \mathrm{mmol} / 1$, post-prandial blood glucose $>11.1 \mathrm{mmol} / 1$ or used to on anti-diabetic treatments. Hyperlipidemia was defined as abnormally elevated levels of any or all lipids or lipoproteins in the blood and needed treatment with lipid-lowering therapy. The plasma was obtained by centrifugation at $200 \mathrm{x} \mathrm{g}$ for $10 \mathrm{~min}$ at $15^{\circ} \mathrm{C}$, and was reserved at $-80^{\circ} \mathrm{C}$. All plasma samples underwent 2 freeze/thaw cycles. Measurements of the total cholesterol, HDL-C and triglycerides in the plasma were conducted by biochemical assays using a Beckman CX5 Automated Analyzer (Beckman Coulter, Inc., Brea, CA, USA). The quantification of apoA-II, serum amyloid A (SAA) and apoC-III in the individual HDL samples was conducted by an immunoblotting assay. A sample containing $10 \mu \mathrm{g}$ total proteins was separated by $10 \%$ SDS-PAGE and blotted onto a nitrocellulose membrane. Anti-apoA-II (ab109897), anti-SAA (ab190802) and anti-apoC-III (ab76305) antibodies (all from Abcam, Cambridge, UK) were used as the primary antibodies. The primary antibodies were incubated at $4^{\circ} \mathrm{C}$ overnight. Horseradish peroxidase-conjugated goat anti-rabbit monoclonal antibody (cat. no. sc-2004; Santa Cruz Biotechnology, Inc., Dallas, TX, USA; 1:1,000) was used as the secondary antibody. The secondary antibody was incubated at $25^{\circ} \mathrm{C}$ for $1 \mathrm{~h}$. Antibody binding was detected using a Super Signal West Pico kit (Pierce; Thermo Fisher Scientific, Inc., Waltham, MA, USA) according to the manufacturer's protocol.

HDL isolation from plasma. HDL particles (density, $1.063-1.21 \mathrm{~g} / \mathrm{ml}$ ) in the plasma were separated by sequential density ultracentrifugation using potassium bromide $(\mathrm{KBr})$ as described previously (28). Briefly, the plasma density was adjusted to $1.3 \mathrm{~g} / \mathrm{ml}$ with $\mathrm{KBr}$, and normal saline $(1.006 \mathrm{~g} / \mathrm{ml})$ was layered over the adjusted plasma to form a discontinuous $\mathrm{NaCl} / \mathrm{KBr}$ density gradient. The tubes loaded with sample and gradient were placed in the P40ST rotor of an ultracentrifuge (model CP70MX; Hitachi, Ltd., Tokyo, Japan) and were centrifuged at $350,000 \mathrm{x}$ g for $3.5 \mathrm{~h}$ at $4^{\circ} \mathrm{C}$. The HDL layer was collected. The protein concentration was measured in triplicate using a Micro BCA kit (Pierce; Thermo Fisher Scientific, Inc.). The purity of the HDL was evaluated by $12 \%$ sodium dodecyl sulfate-polyacrylamide gel electrophoresis (SDS-PAGE) and western blot analysis using goat anti-apoA-I polyclonal antibody (ab64308; Abcam) and quantified through the measurement of apoA-I content by nephelometry (Dimension XPand; Siemens Healthineers, Erlangen, Germany).

Mass spectrometry (MS). The specific gel band was excised and destained with $25 \mathrm{mM} \mathrm{NH}_{4} \mathrm{HCO}_{3}$ in $50 \%$ acetonitrile. Proteins were reduced by $10 \mathrm{mM}$ dithiothreitol at $56^{\circ} \mathrm{C}$ for $30 \mathrm{~min}$ and alkylated using $50 \mathrm{mM}$ iodoacetamide at $25^{\circ} \mathrm{C}$ for $30 \mathrm{~min}$. After drying in $100 \%$ acetonitrile, the gel band was digested using sequencing grade trypsin (Promega Corporation, Madison, WI, USA) at $37^{\circ} \mathrm{C}$ overnight. The extracted peptides were suspended in $0.1 \%$ formic acid and subjected to nano liquid chromatography-MS/MS analysis. Peptides were eluted with a linear gradient from 5 to $40 \%$ of $100 \%$ acetonitrile and $0.1 \%$ formic acid at a flow rate of $300 \mathrm{nl} / \mathrm{min}$ using a self-made $100 \mu \mathrm{m}$ x $10 \mathrm{~cm}$ reversed-phase $\mathrm{C} 18$ fused silica emitter. The data-dependent mass spectra were acquired with an LTQ Orbitrap Elite mass spectrometer equipped with a nano-electrospray ion source (Thermo Fisher Scientific, Inc.). Raw mass spectra files were processed with Proteome Discoverer 1.4 (Thermo Fisher Scientific, Inc.) and searched using the SEQUEST search engine (29) against the human Uniprot database (version 2014_02; http://www.uniprot. org/). The precursor ion mass tolerance was set to $10 \mathrm{ppm}$, 


\section{Uniprot accession}

\begin{tabular}{|l}
\hline P0DJI9 \\
\hline P35542 \\
\hline I3L4M5 \\
\hline P02679-2 \\
\hline P02656 \\
\hline F8WFB2 \\
\hline P01877 \\
\hline C9JA05 \\
\hline K7EKU0 \\
\hline P02675 \\
\hline P60709 \\
\hline P0DJI8 \\
\hline K7ERI9 \\
\hline P10909-3 \\
\hline P55058-3 \\
\hline P02748 \\
\hline F5GXS5 \\
\hline F5GXQ1 \\
\hline P02671-2 \\
\hline G8JL88 \\
\hline F8W6P5 \\
\hline P01024 \\
\hline P69905 \\
\hline P01860 \\
\hline F8WAS2 \\
\hline Q5T985 \\
\hline P01834 \\
\hline F5GXS0 \\
\hline P02765 \\
\hline P0CG04 \\
\hline P01620 \\
\hline E9PQD6 \\
\hline P08519 \\
\hline
\end{tabular}

P00738

$\mathrm{H} 7 \mathrm{C} 5 \mathrm{H} 1$

P02649

P05090

P06727

P00739

E9PFZ2

A0M8Q6

E5RHH8

P04004

I3L1Q6

P55058

P04196

S4R407

C9JIX1

$\mathrm{P} 02655$

$\mathrm{P} 02652$

C9JX71

$\mathrm{P} 02647$

$\mathrm{P} 02654$

E7EVI1

Q7Z5M8-2
Serum amyloid A-2 protein

Serum amyloid $A-4$ protein

5-azacytidine-induced protein 1 (Fragment) Is oform Gamma-A of Fibrinogen gamma chain Apolipoprotein C-II SEC14 domain and spectrin repeat-containing protein 1 Ig alpha- 2 chain $\mathrm{C}$ region Immunoglobulin $\mathrm{J}$ chain (Fragment) $\mathrm{G}$ patch domain-containing protein 8 (Fragment) Fibrinogen beta chain Actin, cytoplasmic 1 Serum amyloid $\mathrm{A}-1$ protein Truncated apolipoprotein C-I (Fragment) Isoform 3 of Clusterin Isoform 3 of Phospholipid transfer protein

Complement component C9 Apolipoprotein $\mathrm{F}$ $35 \mathrm{kDa}$ inter-alpha-tryps in inhibitor heavy chain $\mathrm{H} 4$ Isoform 2 of Fibrinogen alpha chain Apolipoprotein L1 LW-hemorphin-7 (Fragment) Complement $\mathrm{C} 3$

Hemoglobin subunit alpha

Ig gamma- 3 chain $\mathrm{C}$ region Inter-alpha-tryps in inhibitor heavy chain $\mathrm{H} 1$ Inter-alpha-trypsin inhibitor heavy chain $\mathrm{H}_{2}$ Ig kappa chain $\mathrm{C}$ region Complement C4-B Alpha-2-HS-glycoprotein Ig lambda-1 chain $\mathrm{C}$ regions Ig kappa chain V-III region SIE Serum amyloid $\mathrm{A}$ protein Apolipoprotein(a)
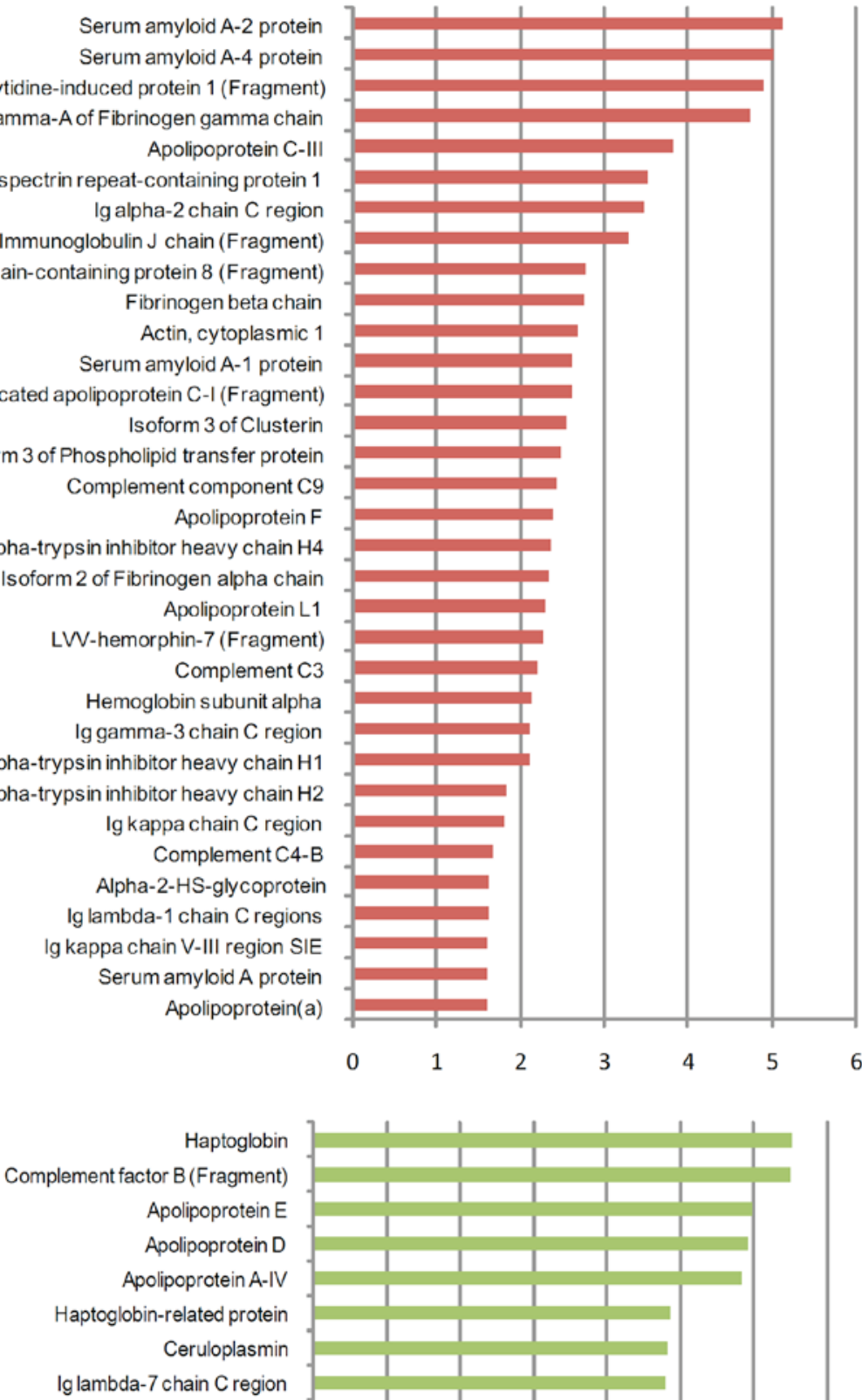

Cell cycle and apoptosis regulator protein 2

Vitronectin

Phos phatidylcholine-sterol acyltransferase (Fragment)

Phospholipid transfer protein

Histidine-rich glycoprotein

Tripartite motif-containing protein 45 (Fragment) $\mathrm{R} 3 \mathrm{H}$ domain-containing protein 1 (Fragment)

Apolipoprotein C-II

Apolipoprotein A-II

Apolipoprotein D (Fragment) Apolipoprotein $\mathrm{A}-\mathrm{I}$

Apolipoprotein C-I

Double-stranded RNA-binding protein Staufen homolog 2

Isoform 2 of Abhydrolase domain-containing protein 12B

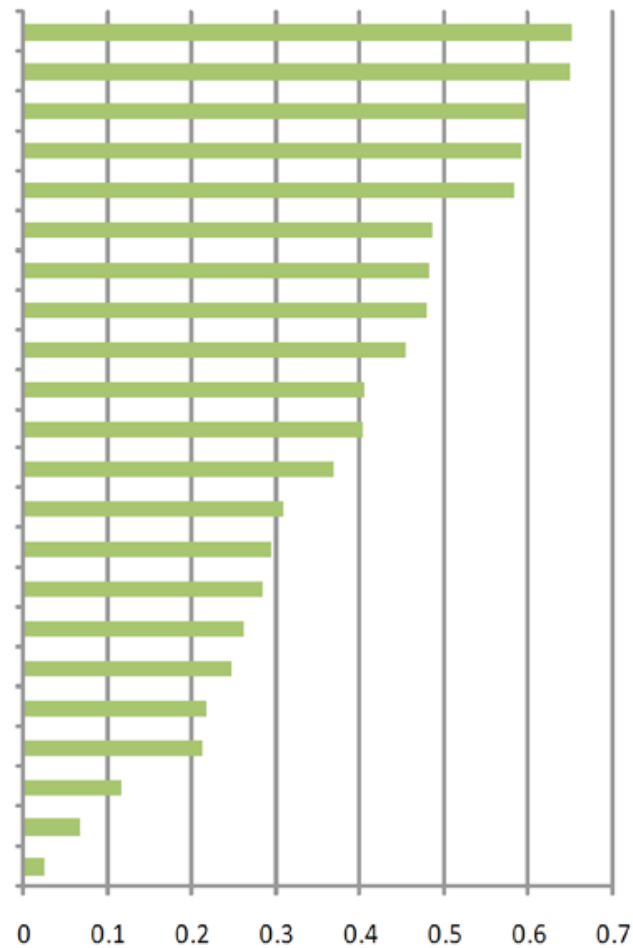

Figure 1. Relative abundance of proteins identified by MS from the HDL of patients with LACI and healthy controls. Data are from 12 subjects with LACI and 12 controls. The relative abundance of the HDL-associated proteins was assessed as described in Materials and methods. MS, mass spectroscopy; HDL, high-density lipoprotein; LACI, lacunar infarction. 
and the MS/MS tolerance was 0.02 Da. Relative quantification was based on the ratio of the areas under the reporter peaks. Protein-protein interaction networks of differentially expressed proteins were constructed using STRING 9.1 (http:// string-db.org/). The name of each individual protein was given as a query to the STRING database and the corresponding PPI information was retrieved by enabling different prediction methods. The networks were made with a confidence cutoff of 0.4 .

THP-1 cell adhesion assay and determination of adhesion molecules by western blot analysis. The method used was as described previously (30). THP-1 monocytic cells were labeled with $3 \mu \mathrm{g} / \mathrm{ml}$ 2',7'-bis-(2-carboxyethyl)-5-(and-6)-carboxyfluorescein, acetoxymethyl ester at $37^{\circ} \mathrm{C}$ for $30 \mathrm{~min}$. The labeled cells were washed three times with phosphate-buffered saline (PBS), and were then resuspended in RPMI-1640 (R1640; Gibco, Paisley, UK) containing $0.1 \%$ bovine serum albumin (Gibco). The cell suspensions were overlaid $\left(1.5 \times 10^{6}\right.$ cells $/ \mathrm{ml}, 500 \mu \mathrm{l} /$ well $)$ on confluent monolayers of human umbilical vein endothelial cells (HUVECs; CRL-1730; ATCC, Manassas, VA, USA) that had been grown in 12-well plates and treated with various types of HCL: HDL from the control group $\left(\mathrm{HDL}_{\mathrm{n}}\right), \mathrm{HDL}$ from LACI patients $\left(\mathrm{HDL}_{\mathrm{LI}}\right)$ and HDL with an elevated level of apoC-III [HDL/apoC-III; obtained after incubation of HDL with apoC-III $(100 \mu \mathrm{g} / \mathrm{ml}$; TP306566; Origene, Beijing, China) for $2 \mathrm{~h}$ at $\left.37^{\circ} \mathrm{C}\right]$. PBS treatment was used as a negative control. Following incubation for $15 \mathrm{~min}$ at $37^{\circ} \mathrm{C}$, nonadherent THP-1 monocytic cells were removed by washing five times with prewarmed RPMI-1640 containing $0.1 \%$ bovine serum albumin. The number of THP-1 monocytic cells on the HUVECs was counted in four views using fluorescence microscopy at x100 magnification to determine the number of adhering cells.

Western blot analysis was conducted to investigate the expression of vascular cell adhesion molecule-1 (VCAM-1) by the endothelial cells. The cells were washed twice with cold PBS, and the cytoplasmic proteins were collected using Nucleoprotein Extraction kit (BSP009; Shenggong, Shanghai, China) following the manuals. The proteins were quantified using Protein Quantitative kit (DQ111-01; Transgen Biotech, Beijing, China) following the manuals. A sample containing $30 \mu \mathrm{g}$ cytoplasmic proteins was separated by 10 or $15 \%$ SDS-PAGE and blotted onto a nitrocellulose membrane. Rabbit monoclonal antibody to VCAM-1 (ab134047; 1:1,000; Abcam) was used as the primary antibody and was incubated at $4^{\circ} \mathrm{C}$ overnight. Horseradish peroxidase-conjugated goat anti-rabbit monoclonal antibody (1:1,000; cat. no. sc-2004; Santa Cruz Biotechnology, Inc.) was used as the secondary antibody and was incubated at $25^{\circ} \mathrm{C}$ for $1 \mathrm{~h}$. Antibody binding was detected using a Super Signal West Pico kit (Pierce; Thermo Fisher Scientific, Inc.) according to the manufacturer's protocol.

Statistical analysis. Data are presented as the mean \pm standard deviation or number (\%). Continuous data were analyzed using t-tests, while discrete data were analyzed using Chi-square tests. One-way ANOVA method was used for comparison of multiple groups. $\mathrm{P}<0.05$ was considered to indicate a statistically significant difference. The SPSS 16.0 software package (SPSS, Inc., Chicago, IL, USA) was used for data analysis.
Table I. Clinical characteristics of study subjects.

\begin{tabular}{lcc}
\hline Features & $\begin{array}{c}\text { LACI patients } \\
(\mathrm{n}=12)\end{array}$ & $\begin{array}{c}\text { control } \\
(\mathrm{n}=12)\end{array}$ \\
\hline Age (years) & $57 \pm 6$ & $55 \pm 4$ \\
Male, $\mathrm{n}(\%)$ & $7(58.33)$ & $7(58.33)$ \\
DM, $(\%)$ & $3(25)$ & $3(25)$ \\
Hyperlipidemia, $\mathrm{n}(\%)$ & $6(50)$ & $4(33.33)$ \\
Total cholesterol $(\mathrm{mg} / \mathrm{dl})$ & $4.16 \pm 1.09$ & $4.30 \pm 0.63$ \\
Triglyceride $(\mathrm{mg} / \mathrm{dl})$ & $1.65 \pm 0.69$ & $1.70 \pm 0.55$ \\
HDL cholesterol $(\mathrm{mmol} / \mathrm{l})$ & $1.04 \pm 0.24$ & $1.05 \pm 0.37$ \\
Fasting blood glucose $(\mathrm{mg} / \mathrm{dl})$ & $5.59 \pm 1.41$ & $6.08 \pm 1.71$ \\
Creatinine $(\mathrm{mg} / \mathrm{dl})$ & $93.90 \pm 14.32$ & $90.02 \pm 15.17$
\end{tabular}

Data expressed as mean \pm standard deviation or number (\%). LACI, lacunar infarction; DM, diabetes mellitus; HDL, high-density lipoprotein.

Gene Ontology (GO) analysis was conducted using DAVID bioinformatics resources (http://david.abcc.ncifcrf.gov) as described previously $(31,32)$.

\section{Results}

Characteristics of the study population. The characteristics of the patients and controls are summarized in Table I. No difference in the proportions of sex, DM and hyperlipidemia was observed between the two groups. In addition, there was no difference in the plasma total cholesterol, triglyceride, HDL-C, fasting blood glucose and serum creatinine levels between the LACI and control subjects.

HDL proteomics. Proteins that had a differential expression of $\geq 1.5$-fold or $\leq 0.67$-fold relative in the LACI samples compared with the control samples were considered as differentially expressed. In total, 55 proteins were identified to be differentially expressed in the LACI and control groups (Fig. 1). Among these 55 proteins, 33 were upregulated and 22 were downregulated in the patients with LACI compared with the control subjects. The level of LACI's haptoglobin was less compared to $1 / 5$ of the control subjects.

The GO classification system was used to classify the identified proteins into different clusters according to biological processes and molecular functions. Fig. 2 shows the GO categories of the identified proteins. The differentially identified proteins were associated with numerous molecular functions, including lipid and cholesterol metabolism, inflammatory response, the complement and coagulation pathway, hemostasis, metal ion metabolism and endopeptidase inhibitory activity. Proteins associated with lipid/cholesterol transport and metabolism exhibited the most significant changes.

Fig. 3 shows an organic network that graphically depicts statistically significant correlations between identified proteins (nodes) as connecting lines (edges). Long/thin lines indicate weak correlations. Short/thick lines indicate strong correlations; tightly correlated proteins appear in the same color in 
A

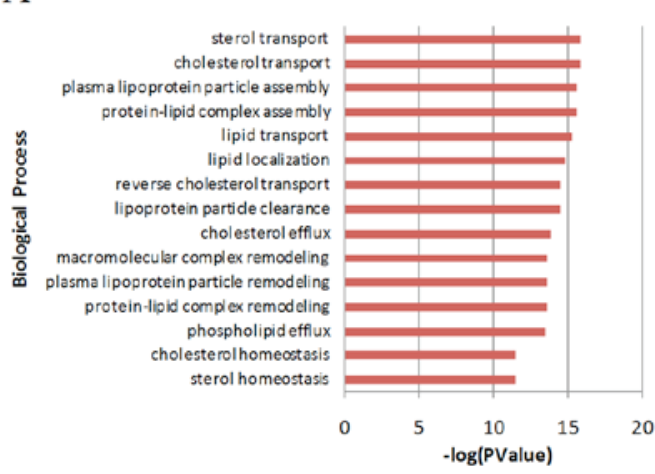

\begin{tabular}{|cccc|}
\hline Term & Count & $\%$ & PValue \\
\hline GO:0015918 sterol transport & 10 & 27.03 & $1.49 \mathrm{E}-16$ \\
\hline GO:0030301 cholesterol transport & 10 & 27.03 & $1.49 \mathrm{E}-16$ \\
\hline GO:0034377 plasma lipoprotein particle assembly & 8 & 21.62 & $2.57 \mathrm{E}-16$ \\
\hline GO:0065005 protein-lipid complex assembly & 8 & 21.62 & $2.57 \mathrm{E}-16$ \\
\hline GO:0006869 lipid transport & 13 & 35.14 & $6.38 \mathrm{E}-16$ \\
\hline GO:0010876 lipid localization & 13 & 35.14 & $1.69 \mathrm{E}-15$ \\
\hline GO:0043691 reverse cholesterol transport & 8 & 21.62 & $3.68 \mathrm{E}-15$ \\
\hline GO:0034381 lipoprotein particle clearance & 8 & 21.62 & $3.68 \mathrm{E}-15$ \\
\hline GO:0033344 cholesterol efflux & 8 & 21.62 & $1.61 \mathrm{E}-14$ \\
\hline GO:0034367 macromolecular complex remodeling & 8 & 21.62 & $2.48 \mathrm{E}-14$ \\
\hline GO:0034369 plasma lipoprotein particle remodeling & 8 & 21.62 & $2.48 \mathrm{E}-14$ \\
\hline GO:0034368 protein-lipid complex remodeling & 8 & 21.62 & $2.48 \mathrm{E}-14$ \\
\hline GO:0033700 phospholipid efflux & 7 & 18.92 & $3.29 \mathrm{E}-14$ \\
\hline GO:0042632 cholesterol homeostasis & 8 & 21.62 & $3.92 \mathrm{E}-12$ \\
\hline GO:0055092 sterol homeostasis & 8 & 21.62 & $3.92 \mathrm{E}-12$ \\
\hline
\end{tabular}

$\mathrm{B}$

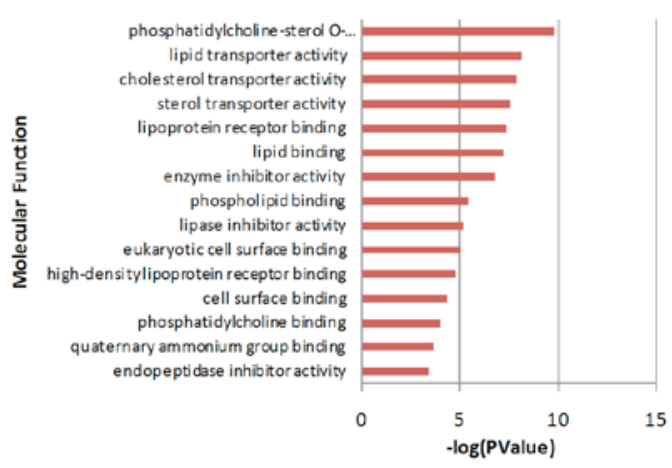

\begin{tabular}{|cccc|}
\hline Term & Count & $\%$ & PValue \\
\hline $\begin{array}{c}\text { GO:0060228 phosphatidylcholine-sterol O- } \\
\text { acyltransferase activator activity }\end{array}$ & 5 & 13.51 & $1.33 \mathrm{E}-10$ \\
\hline GO:0005319 lipid transporter activity & 7 & 18.92 & $6.85 \mathrm{E}-09$ \\
\hline GO:0017127 cholesterol transporter activity & 5 & 13.51 & $1.30 \mathrm{E}-08$ \\
\hline GO:0015248 sterol transporter activity & 5 & 13.51 & $2.62 \mathrm{E}-08$ \\
\hline GO:0070325 lipoprotein receptor binding & 5 & 13.51 & $3.56 \mathrm{E}-08$ \\
\hline GO:0008289 lipid binding & 11 & 29.73 & $5.22 \mathrm{E}-08$ \\
\hline GO:0004857 enzyme inhibitor activity & 9 & 24.32 & $1.64 \mathrm{E}-07$ \\
\hline GO:0005543 phospholipid binding & 7 & 18.92 & $3.27 \mathrm{E}-06$ \\
\hline GO:0055102 lipase inhibitor activity & 4 & 10.81 & $5.50 \mathrm{E}-06$ \\
\hline GO:0043499 eukaryotic cell surface binding & 4 & 10.81 & $8.19 \mathrm{E}-06$ \\
\hline GO:0070653 high-density lipoprotein receptor binding & 3 & 8.11 & $1.65 \mathrm{E}-05$ \\
\hline GO:0043498 cell surface binding & 4 & 10.81 & $4.32 \mathrm{E}-05$ \\
\hline GO:0031210 phosphatidylcholine binding & 3 & 8.11 & $8.23 \mathrm{E}-05$ \\
\hline GO:0050997 quatemary ammonium group binding & 3 & 8.11 & $1.97 \mathrm{E}-04$ \\
\hline GO:0004866 endopeptidase inhibitor activity & 5 & 13.51 & $3.71 \mathrm{E}-04$ \\
\hline
\end{tabular}

Figure 2. Gene Ontology category enrichments for the differentially expressed proteins in the high-density lipoprotein fraction. (A) Biological process and (B) molecular function of the differentially expressed proteins.

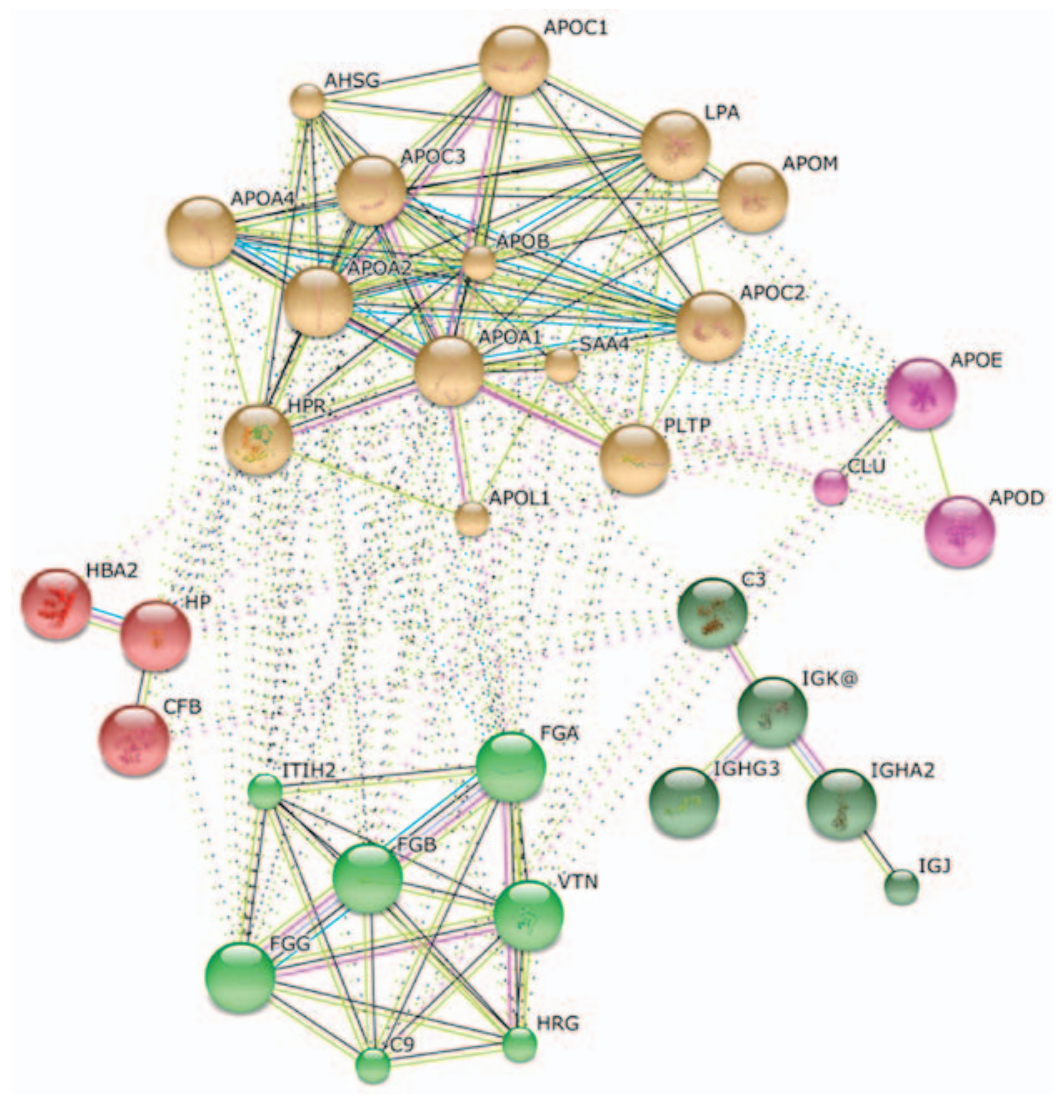

Figure 3. Functional interaction network based on the String database and Gene Ontology classification. The green nodes correspond to proteins involved in hemostasis. The purple nodes correspond to proteins involved in metal binding. The yellow nodes correspond to proteins involved in lipid metabolism. The red nodes correspond to proteins involved in hemoglobin metabolism. The dark green nodes correspond to proteins involved in inflammatory response. 
A

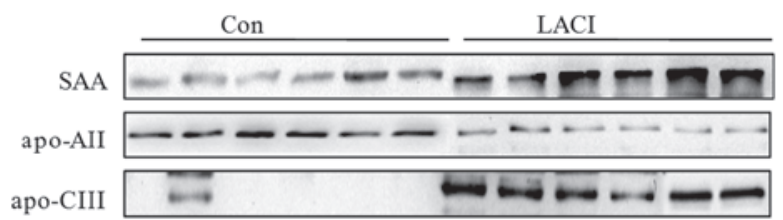

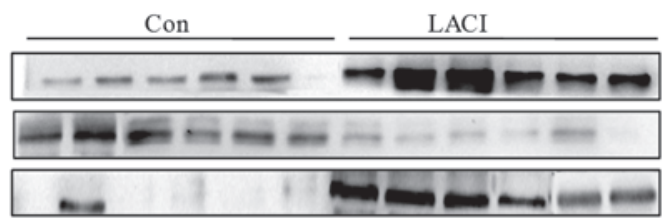

B

SAA

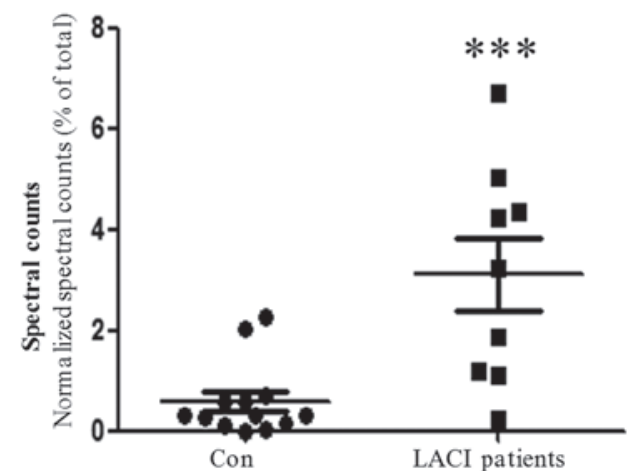

apoC-III

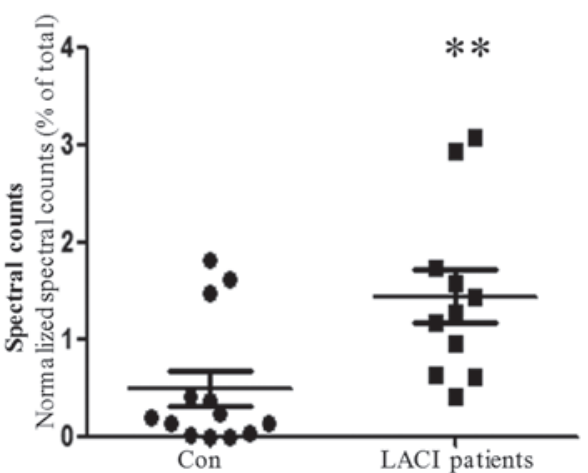

apoA-II

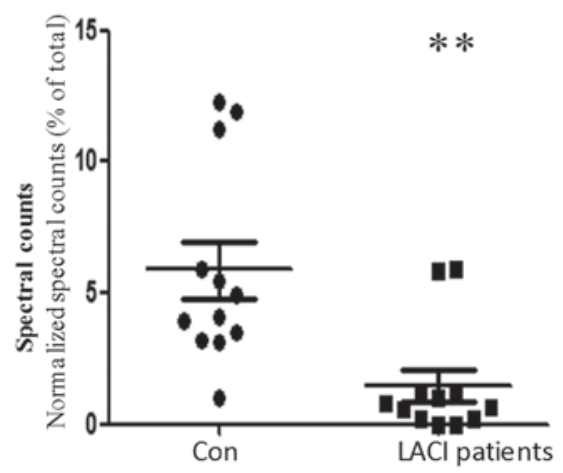

Figure 4. Validation of apoA-II, SAA and apoC-III levels in high-density lipoprotein isolated from control and LACI subjects by western blot analysis. (A) apoA-II, apoC-III and SAA were quantified by western blot analysis. (B) Mass spectometry results of apoA-II, apoC-III and SAA between the patients and controls. ${ }^{* *} \mathrm{P}<0.01$ and ${ }^{* * *} \mathrm{P}<0.001$ vs. the control by a two-tailed Student's t-test. apoA-II, apolipoprotein A-II; SAA, serum amyloid A; apoC-III, apolipoprotein C-III; LACI, lacunar infarction.

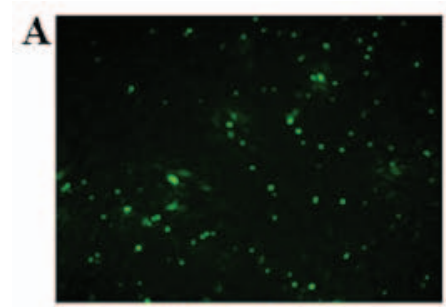

PBS control

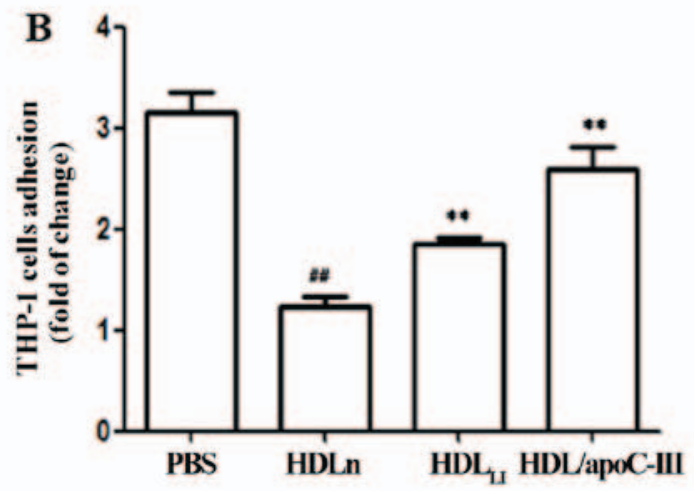

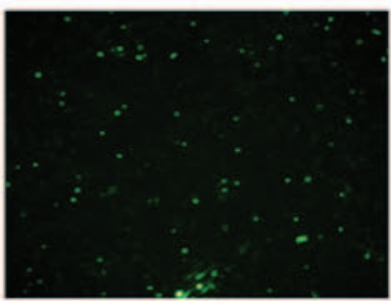

HDL $_{\mathrm{H}}$
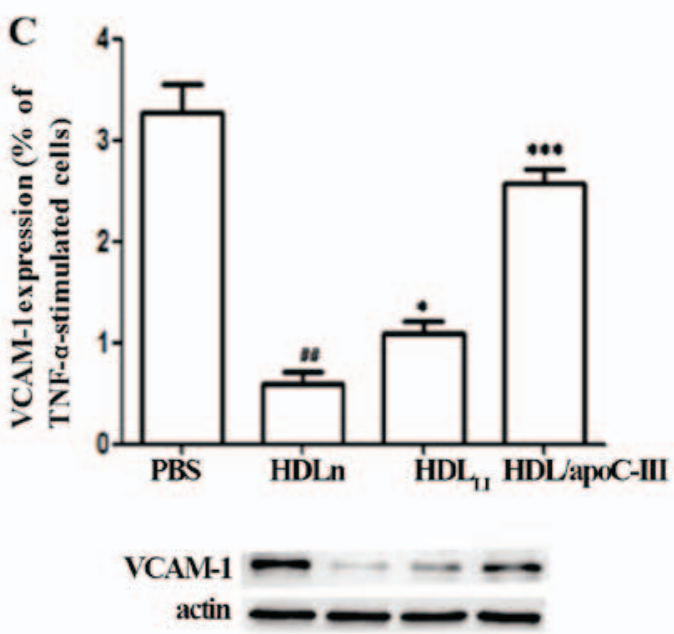

Figure 5. HDL $\mathrm{LI}_{\mathrm{LI}}$ and HDL/apoC-III have impaired ability to inhibit THP-1 cell adhesion. (A) THP-1 cell adhesion to endothelial cells (cells labeled with 2',7'-bis-(2-carboxyethyl)-5-(and-6)-carboxyfluorescein, acetoxymethyl ester). (B) Quantification of the THP-1 cell adhesion and (C) VCAM-1 expression of endothelial cells. ${ }^{*} \mathrm{P}<0.05,{ }^{* *} \mathrm{P}<0.01$ and ${ }^{* * *} \mathrm{P}<0.01$ vs. the PBS control ${ }^{\# \#} \mathrm{P}<0.01$ vs. the PBS control. $\mathrm{HDL}_{\mathrm{n}}$, HDL from the control group; HDL $\mathrm{LI}_{\mathrm{I}}, \mathrm{HDL}$ from patients with lacunar infarction; HDL/apoC-III, HDL with an elevated content of apolipoproten C-III; VCAM-1, vascular cell adhesion molecule-1.

the network. The differentially expressed proteins formed five different functional clusters, indicating an involvement in lipid metabolism, hemostasis, metal binding, hemoglobin metabolism and inflammatory response.
Biochemical confirmation of the differentially expressed proteins. The expression levels of three proteins identified by MS analysis in the majority of the 12 LACI patients were evaluated by western blot assay to validate the differ- 
ence observed. SAA $(\mathrm{P}<0.001)$ and apoC-III $(\mathrm{P}=0.007)$ were significantly upregulated whereas apoA-II $(\mathrm{P}=0.002)$ was significantly downregulated in the LACI patient group compared with the controls in the proteomic analysis. The results of the western blot analysis were in agreement with the MS findings, with the majority of the patients having a decreased level of apoA-II and increased levels of apoC-III and SAA (Fig. 4).

HDL of LACI patients has an increased apoC-III content that impairs its anti-inflammatory function. The treatment of HUVECs with $\mathrm{HDL}_{\mathrm{n}}$ reduced the binding of THP-1 cells to the HUVECs compared with the PBS-treated controls (Fig. 5). However, $\mathrm{HDL}_{\mathrm{LI}}$ had an impaired ability to inhibit the binding of THP-1 cells to HUVECs compared with HDLn $(\mathrm{P}<0.01)$. HDL/apoC-III also exhibited a significantly reduced ability to inhibit the binding of THP-1 cells to HUVECs compared with HDLn $(\mathrm{P}<0.01)$. The expression of VCAM-1 protein exhibited a response to the HDL treatments that paralleled the response of the binding ability. Treatment with HDL/apoC-III induced a significantly higher expression of VCAM-1 compared with $\mathrm{HDL}_{\mathrm{n}}(\mathrm{P}<0.001)$. Treatment with HDLLI induced a significantly higher expression of VCAM-1 compared with HDLn $(\mathrm{P}<0.05)$.

\section{Discussion}

There are $\sim 50$ proteins associated with the HDL fraction that have been identified by previous studies using MS methods $(5,7,8,13,25,33)$. In the present study, 55 differentially expressed proteins were identified, which included the majority of the previously identified proteins $(19,25-28,30,31)$. The proteins identified as being associated with HDL are involved in numerous functions, including lipid metabolism, inflammatory response, the complement and coagulation pathway, and endopeptidase inhibitory activity. Several apolipoproteins and enzymes associated with lipid metabolism were detected, including apoA-I, apoA-II, apoC-III, apoA-IV, apoC-I, apoC-II, apoD, apoJ, apoE, apoF, apoL-I, apoM, phospholipid transfer protein and phosphatidylcholine-sterol acyltransferase. Other proteins that are involved in the inflammation response and oxidative pathways were also identified, including serum amyloid A proteins and certain complement components.

There were 55 proteins that were identified to be differentially expressed between the patients and controls in the present study. Among these proteins, three proteins that were differentially expressed in the majority of the $12 \mathrm{LACI}$ patients were further validated using a biochemical method. The results of western blot analysis validated the increase of apoC-III and SAA, as well as the reduction of apoA-II in the HDL fraction of LACI patients compared with the controls.

Another notable finding in the present study was that an increased level of apoC-III in the HDL of LACI patients was associated with an impaired anti-inflammatory function. ApoC-III is a small apolipoprotein that is synthesized mainly in the liver and circulates in the plasma in association with apoB-containing lipoproteins and HDL (35). The main physiological processes that apoC-III is involved in are inhibition of lipoprotein lipase and hepatic lipase, and inhibition of the hepatic uptake of triglyceride-rich particles (34). Furthermore, apoC-III activates $\beta$-integrin, protein kinase $\mathrm{C} \beta$ and downstream VCAM-1 in monocytes, which increases the adhesion of monocytes to vascular endothelial cells (35). In the present study, the HDL of LACI patients, with its upregulation of apoC-III, had a reduced ability to inhibit leukocyte binding to endothelial cells. Furthermore, ApoC-III-rich HDL did not inhibit monocyte adhesion to endothelial cells, while the HDL of control subjects decreased the adhesion, suggesting that apoC-III in HDL reduces the anti-inflammatory property of HDL. This phenomenon clearly implies that the apoC-III metabolism is changed in cerebrovacular disease.

In addition to a reverse cholesterol transport function, HDL has other vasculoprotective effects, including antioxidative and anti-inflammatory properties $(4,36,37)$. For instance, HDL attenuates low-density lipoprotein (LDL) oxidation, a critical process in the onset and aggravation of atherosclerotic plaques (38). Metal ions, such as iron or copper, may promote lipid peroxidation in the process of LDL oxidation (39). The present study identified a number of proteins associated with metal ion metabolism. The level of haptoglobin was decreased in the HDL fraction of LACI patients compared with that of the control subjects. Haptoglobin is an acute phase protein. It exclusively binds to hemoglobin and releases it into the plasma during physiological and pathological hemolysis, thereby preventing iron- and heme-mediated oxidative side effects $(40,41)$.

In conclusion, the present study revealed the proteomic changes of HDL in patients with LACI. There were 55 proteins that were identified to be quantitatively different between the patients with LACI and the control group, which were mainly associated with the processes of lipid metabolism, the inflammatory response, metal ion homeostasis, and the complement pathway. The expression levels of apoA-II, apoC-III and SAA were validated biochemically, and the results were consistent with the MS data. The ApoC-III enrichment of the HDL in patients with LACI may reduce the adhesion of THP-1 to endothelial cells, and thereby decrease the anti-inflammatory effect of HDL. Future studies with a larger number of subjects are required to determine whether the identified proteins are suitable and relevant risk biomarkers. Furthermore, the underlying mechanism of the apoC-III mediated HDL dysfunction requires elucidation.

\section{References}

1. Havel RJ, Eder HA and Bragdon JH: The distribution and chemical composition of ultracentrifugally separated lipoproteins in human serum. J Clin Invest 34: 1345-1353, 1955.

2. Kontush A and Chapman MJ: Antiatherogenic small, dense HDL--guardian angel of the arterial wall? Nat Clin Pract Cardiovasc Med 3: 144-153, 2006.

3. Davidson WS and Thompson TB: The structure of apolipoprotein A-I in high density lipoproteins. J Biol Chem 282: 22249-22253, 2007.

4. Kontush A and Chapman MJ: Functionally defective highdensity lipoprotein: A new therapeutic target at the crossroads of dyslipidemia, inflammation, and atherosclerosis. Pharmacol Rev 58: 342-374, 2006.

5. Karlsson H, Leanderson P, Tagesson $\mathrm{C}$ and Lindahl M: Lipoproteomics II: Mapping of proteins in high-density lipoprotein using two-dimensional gel electrophoresis and mass spectrometry. Proteomics 5: 1431-1445, 2005.

6. Heller M, Stalder D, Schlappritzi E, Hayn G, Matter U and Haeberli A: Mass spectrometry-based analytical tools for the molecular protein characterization of human plasma lipoproteins. Proteomics 5: 2619-2630, 2005. 
7. Rezaee F, Casetta B, Levels JH, Speijer D and Meijers JC: Proteomic analysis of high-density lipoprotein. Proteomics 6: 721-730, 2006.

8. Vaisar T, Pennathur S, Green PS, Gharib SA, Hoofnagle AN, Cheung MC, Byun J, Vuletic S, Kassim S, Singh P, et al: Shotgun proteomics implicates protease inhibition and complement activation in the antiinflammatory properties of HDL. J Clin Invest 117: 746-756, 2007.

9. Tan Y, Liu TR, Hu SW, Tian D, Li C, Zhong JK, Sun HG, Luo TT, Lai WY and Guo ZG: Acute coronary syndrome remodels the protein cargo and functions of high-density lipoprotein subfractions. PLoS One 9: e94264, 2014.

10. Yan LR, Wang DX, Liu H, Zhang XX, Zhao H, Hua L, Xu P and Li YS: A pro-atherogenic HDL profile in coronary heart disease patients: An iTRAQ labelling-based proteomic approach. PLoS One 9: e98368, 2014.

11. Lepedda AJ, Nieddu G, Zinellu E, De Muro P, Piredda F, Guarino A, Spirito R, Carta F, Turrini F and Formato $M$ : Proteomic analysis of plasma-purified VLDL, LDL, and HDL fractions from atherosclerotic patients undergoing carotid endarterectomy: Identification of serum amyloid $\mathrm{A}$ as a potential marker. Oxid Med Cell Longev 2013: 385214, 2013.

12. Ståhlman M, Fagerberg B, Adiels M, Ekroos K, Chapman JM, Kontush A and Borén J: Dyslipidemia, but not hyperglycemia and insulin resistance, is associated with marked alterations in the HDL lipidome in type 2 diabetic subjects in the DIWA cohort: Impact on small HDL particles. Biochim Biophys Acta 1831: 1609-1617, 2013.

13. Holzer M, Birner-Gruenberger R, Stojakovic T, El-Gamal D, Binder V, Wadsack C, Heinemann A and Marsche G: Uremia alters HDL composition and function. J Am Soc Nephrol 22: 1631-1641, 2011.

14. Mangé A, Goux A, Badiou S, Patrier L, Canaud B, Maudelonde T, Cristol JP and Solassol J: HDL proteome in hemodialysis patients: A quantitative nanoflow liquid chromatography-tandem mass spectrometry approach. PLoS One 7: e34107, 2012.

15. Kopecky C, Genser B, Drechsler C, Krane V, Kaltenecker CC Hengstschläger M, März W, Wanner C, Säemann MD and Weichhart T: Quantification of HDL proteins, cardiac events, and mortality in patients with type 2 diabetes on hemodialysis. Clin J Am Soc Nephrol 10: 224-231, 2015

16. Watanabe J, Charles-Schoeman C, Miao Y, Elashoff D, Lee YY, Katselis G, Lee TD and Reddy ST: Proteomic profiling following immunoaffinity capture of high-density lipoprotein: Association of acute-phase proteins and complement factors with proinflammatory high-density lipoprotein in rheumatoid arthritis. Arthritis Rheum 64: 1828-1837, 2012.

17. Chait A, Han CY, Oram JF and Heinecke JW: Thematic review series: The immune system and atherogenesis. Lipoproteinassociated inflammatory proteins: Markers or mediators of cardiovascular disease? J Lipid Res 46: 389-403, 2005.

18. Chei CL, Yamagishi K, Kitamura A, Kiyama M, Imano H Ohira T, Cui R, Tanigawa T, Sankai T, Ishikawa Y, et al; CIRCS Investigators: High-density lipoprotein subclasses and risk of stroke and its subtypes in Japanese population: The Circulatory Risk in Communities Study. Stroke 44: 327-333, 2013.

19. Ashby DT, Rye KA, Clay MA, Vadas MA, Gamble JR and Barter PJ: Factors influencing the ability of HDL to inhibit expression of vascular cell adhesion molecule-1 in endothelial cells. Arterioscler Thromb Vasc Biol 18: 1450-1455, 1998.

20. Barter PJ, Nicholls S, Rye KA, Anantharamaiah GM, Navab M and Fogelman AM: Antiinflammatory properties of HDL. Circ Res 95: 764-772, 2004

21. Fisher CM: The arterial lesions underlying lacunes. Acta Neuropathol 12: 1-15, 1968

22. Ogata J, Yamanishi H and Ishibashi-Ueda H: Review: Role of cerebral vessels in ischaemic injury of the brain. Neuropathol Appl Neurobiol 37: 40-55, 2011.

23. Sorci-Thomas MG and Thomas MJ: Why targeting HDL should work as a therapeutic tool, but has not. J Cardiovasc Pharmacol 62: 239-246, 2013.

24. Hsieh JY, Chang CT, Huang MT, Chang CM, Chen CY, Shen MY, Liao HY, Wang GJ, Chen CH, Chen CJ, et al: Biochemical and functional characterization of charge-defined subfractions of high-density lipoprotein from normal adults. Anal Chem 85 : 11440-11448, 2013.
25. Davidson WS, Silva RA, Chantepie S, Lagor WR, Chapman MJ and Kontush A: Proteomic analysis of defined HDL subpopulations reveals particle-specific protein clusters: Relevance to antioxidative function. Arterioscler Thromb Vasc Biol 29 870-876, 2009.

26. Patel B and Markus HS: Magnetic resonance imaging in cerebral small vessel disease and its use as a surrogate disease marker. Int J Stroke 6: 47-59, 2011.

27. Turin TC, Kita Y, Rumana N, Nakamura Y, Takashima N, Ichikawa M, Sugihara H, Morita Y, Hirose K, Okayama A, et al: Ischemic stroke subtypes in a Japanese population: Takashima Stroke Registry, 1988-2004. Stroke 41: 1871-1876, 2010.

28. Liu D, Ji L, Tong X, Pan B, Han JY, Huang Y, Chen YE, Pennathur S, Zhang Y and Zheng L: Human apolipoprotein A-I induces cyclooxygenase-2 expression and prostaglandin I-2 release in endothelial cells through ATP-binding cassette transporter A1. Am J Physiol Cell Physiol 301: C739-C748, 2011.

29. Eng JK, McCormack AL and Yates JR: An approach to correlate tandem mass spectral data of peptides with amino acid sequences in a protein database. J Am Soc Mass Spectrom 5: 976-989, 1994

30. Kimura T, Tomura H, Mogi C, Kuwabara A, Damirin A Ishizuka T, Sekiguchi A, Ishiwara M, Im DS, Sato K, et al: Role of scavenger receptor class B type I and sphingosine 1-phosphate receptors in high density lipoprotein-induced inhibition of adhesion molecule expression in endothelial cells. J Biol Chem 281: 37457-37467, 2006.

31. Huang W, Sherman BT and Lempicki RA: Bioinformatics enrichment tools: Paths toward the comprehensive functional analysis of large gene lists. Nucleic Acids Res 37: 1-13, 2009.

32. Franceschini A, Szklarczyk D, Frankild S, Kuhn M, Simonovic M, Roth A, Lin J, Minguez P, Bork P, von Mering C, et al: STRING v9.1: Protein-protein interaction networks, with increased coverage and integration. Nucleic Acids Res 41: D808-D815, 2013.

33. Gordon SM, Deng J, Lu LJ and Davidson WS: Proteomic characterization of human plasma high density lipoprotein fractionated by gel filtration chromatography. J Proteome Res 9: 5239-5249, 2010.

34. Bernelot Moens SJ, van Capelleveen JC and Stroes ESG: Inhibition of ApoCIII: The next PCSK9? Curr Opin Lipidol 25: 418-422, 2014.

35. Kawakami A and Yoshida M: Apolipoprotein CIII links dyslipidemia with atherosclerosis. J Atheroscler Thromb 16: 6-11, 2009.

36. Feig JE, Shamir R and Fisher EA: Atheroprotective effects of HDL: Beyond reverse cholesterol transport. Curr Drug Targets 9: 196-203, 2008.

37. Ansell BJ, Fonarow GC and Fogelman AM: The paradox of dysfunctional high-density lipoprotein. Curr Opin Lipidol 18: 427-434, 2007.

38. Watson AD, Berliner JA, Hama SY, La Du BN, Faull KF, Fogelman AM and Navab M: Protective effect of high density lipoprotein associated paraoxonase. Inhibition of the biological activity of minimally oxidized low density lipoprotein. J Clin Invest 96: 2882-2891, 1995.

39. Blokhina O, Virolainen E and Fagerstedt KV: Antioxidants, oxidative damage and oxygen deprivation stress: A review. Ann Bot (Lond) 91: 179-194, 2003.

40. Katoh N and Nakagawa H: Detection of haptoglobin in the highdensity lipoprotein and the very high-density lipoprotein fractions from sera of calves with experimental pneumonia and cows with naturally occurring fatty liver. J Vet Med Sci 61: 119-124, 1999.

41. Nielsen MJ, Petersen SV, Jacobsen C, Oxvig C, Rees D, Møller HJ and Moestrup SK: Haptoglobin-related protein is a high-affinity hemoglobin-binding plasma protein. Blood 108: 2846-2849, 2006.

This work is licensed under a Creative Commons Attribution-NonCommercial-NoDerivatives 4.0 International (CC BY-NC-ND 4.0) License. 